\title{
Can Children Recognize Pride?
}

\author{
Jessica L. Tracy, Richard W. Robins, and Kristin H. Lagattuta \\ University of California, Davis
}

\begin{abstract}
Recent research has shown that pride, like the "basic" emotions of anger, disgust, fear, happiness, sadness, and surprise, has a distinct, nonverbal expression that can be recognized by adults (J. L. Tracy \& R. W. Robins, 2004b). In 2 experiments, the authors examined whether young children can identify the pride expression and distinguish it from expressions of happiness and surprise. Results suggest that (a) children can recognize pride at above-chance levels by age 4 years; (b) children recognize pride as well as they recognize happiness; (c) pride recognition, like happiness and surprise recognition, improves from age 3 to 7 years; and (d) children's ability to recognize pride cannot be accounted for by the use of a process of elimination (i.e., an exclusion rule) to identify an unknown entity. These findings have implications for the development of emotion recognition and children's ability to perceive and communicate pride.
\end{abstract}

Keywords: pride, self-conscious emotion, emotion recognition, child development, nonverbal expression

One of the landmark events in emotion research was the discovery that a small set of "basic" emotions, including anger, fear, happiness, disgust, sadness, and surprise, have universally recognized nonverbal expressions (Ekman, Sorenson, \& Friesen, 1969). In a series of experiments, we recently found evidence for an additional recognizable emotion expression: pride. Using both forced-choice and open-ended response methods, we found that the pride expression can be recognized by adult judges at rates comparable to recognition of the basic emotions and is reliably distinguished from the similar expression of happiness (Tracy \& Robins, 2004b). The prototypical pride expression includes a small, non-Duchenne smile, head tilted slightly back, a visibly expanded posture, and arms either raised above the head with hands in fists or at sides with hands placed firmly on the hips.

The present research examines the age at which individuals acquire the ability to recognize the pride expression and distinguish it from related emotion expressions. ${ }^{1}$ Previous studies have shown that 4-year-olds can recognize the basic emotion expressions (Camras \& Allison, 1985; Felleman, Barden, Carlson, Rosenberg, \& Masters, 1983; Izard, 1971), so determining whether pride recognition emerges at the same age would provide insights about its similarity to the basic emotions. In addition, knowing when children begin to identify pride in others may lead to a better understanding of the role of pride in early social interactions, peer relations, social comparison processes, and achievement-oriented and status-related behaviors.

Jessica L. Tracy, Richard W. Robins, and Kristin H. Lagattuta, Department of Psychology, University of California, Davis.

This research was supported by National Institute on Aging Grant AG022057. Jessica L. Tracy was supported by a predoctoral fellowship from National Institute of Mental Health Grant T32 MH2006. We thank Ross Thompson for helpful comments on this article.

Correspondence concerning this article should be addressed to Jessica L. Tracy, Department of Psychology, University of California, Davis, CA 95616-8686. E-mail: jltracy@ucdavis.edu
At what age should we expect pride recognition to emerge? Two lines of research guided our expectations. First, several studies have explored the development of pride by coding the nonverbal behaviors shown by children after an achievement. By 3 years of age, children begin to display expressions resembling pride, including an expanded posture, raised arms, open hands, and upward gaze (e.g., Belsky \& Domitrovich, 1997; Lewis, Alessandri, \& Sullivan, 1992; Stipek, Recchia, \& McClintic, 1992). The presence of these displays makes it likely that 3 -year-olds experience pride and plausible that they have some conceptual understanding of it. A second line of research has examined children's ability to recognize basic emotion expressions, by asking them to match photographs of expressions with target emotion words (e.g., choosing the sad face when the experimenter says "sad") or with emotion-eliciting situations (e.g., pairing a happy expression with a birthday party). These studies have shown that children as young as 3 years can recognize happiness (Smiley \& Huttenlocher, 1989) and that by 4 or 5 years of age children accurately identify all six basic-emotion expressions (Camras \& Allison, 1985; Felleman et al., 1983; Izard, 1971). ${ }^{2}$ On the basis of these findings, we might

\footnotetext{
${ }^{1}$ Throughout this article, we use the term recognize to refer to an individual's ability to verbally apply a single-word emotion term (e.g., "pride") to a particular expression. Other forms of recognition, such as the application of contextual stories to expressions, may indicate the presence of different underlying cognitive processes. However, given that ours is the first exploration of pride recognition in children, we ask the most basiclevel question in the study of recognition, that is, Do children label photos of the pride expression with the word 'pride'?

${ }^{2}$ In addition to studies that examine emotion recognition in terms of verbal labeling, there is also a literature showing that infants as young as 5 to 7 months of age look significantly longer at displays where the prosody of a voice matches the emotional expression of the face (e.g., a happy-sounding voice with a happy face; see Walker-Andrews \& Dickson, 1997). However, such studies are not directly relevant to the question of whether children can verbally recognize emotion expressions, which is the focus of the present research.
} 
expect children to have some understanding of pride and to be able to identify its expression beginning around age 3 to 5 years.

There are, however, several reasons why pride may not be recognized as early as the basic emotions. First, it has a more complicated expression that, unlike basic emotion expressions, requires nonfacial components (Tracy \& Robins, 2004b). Second, children do not display pride after success until around age 2 to 3 years, whereas they display most of the basic emotions within the first 6 months of life (Lewis, 2000; Reissland \& Harris, 1991; Stipek et al., 1992). Third, pride, and other self-conscious emotions, are considered to be more cognitively complex than the basic emotions because they may require the capacity to form stable self-representations, to reflect on one's self-representations (i.e., self-awareness), to evaluate the self in comparison with social standards, and to make attributions about whether the self is responsible for the outcome (Campos, Barrett, Lamb, Goldsmith, \& Stenberg, 1983; Graham \& Weiner, 1986; Keltner \& Buswell, 1997; Lewis, 2000; Tracy \& Robins, 2004a). One of the primary markers of self-awareness-mirror self-recognition-is not evident until at least 18 months of life (Lewis \& Brooks-Gunn, 1979), and more complex forms of self-understanding and self-attribution only appear around 2.5 to 3 years of age (Mascolo \& Fischer, 1995; Stipek et al., 1992). ${ }^{3}$ Finally, linguistic analyses show that the age of acquisition for words such as pride is later than for basic-emotion words, and children begin to talk about pride later than they talk about emotions such as happiness and sadness (Bretherton \& Beeghly, 1982). Given these differences, it is not clear whether pride recognition would emerge as early as basicemotion recognition.

The present research aims to (a) determine the age at which children first recognize the pride expression; (b) chart age differences in pride-recognition rates across childhood; (c) determine whether recognition rates for pride are comparable to recognition rates for two basic emotions, happiness and surprise; and (d) determine whether developmental changes in recognition rates across childhood are similar for all three of these emotions. To address these aims, we conducted two experiments that examined age differences in recognition rates for pride, happiness, and surprise expressions in children ages 3 to 7 years.

We included happiness and surprise expressions for several reasons. First, like pride, happiness is a positive emotion, so including it as a "distractor" allowed us to determine whether children can distinguish between two similar positive expressions. Indeed, adults most often confuse the pride expression with the happiness expression (Tracy \& Robins, 2004b). More generally, the inclusion of happiness prevents participants from simply gleaning correct answers by discriminating among oppositely valenced emotions. Second, happiness is the expression that is verbally recognized the earliest and that typically generates the highest recognition rates among adults (Ekman et al., 1969; Smiley \& Huttenlocher, 1989), so its inclusion provides a stringent test of the hypothesis that pride recognition is comparable to basic-emotion recognition. Surprise was included as a second "distractor" because its expression, like that of pride, may include the body (arms raised), as well as the face. Finally, the inclusion of both happiness and surprise allowed us to replicate previous findings of accurate recognition of happiness by age 3 , accurate recognition of surprise by age 4 , and an increasing level of recognition for both emotions across childhood (e.g., Felleman et al., 1983; Harrigan, 1984; Izard, 1971; Odom \& Lemond, 1972).

\section{Experiment 1}

\section{Method}

Participants. Fifty children (47\% girls) between age 3 and 7 years participated in the experiment, including nine 3 -year-olds (age range $=3$ years to 3 years, 11 months; $M=3$ years, 6 months), ten 4 -year-olds (range $=4$ years, 4 months to 4 years, 11 months; $M=4$ years, 8 months), fifteen 5 -year-olds (range $=5$ years to 5 years, 10 months; $M=5$ years, 4 months), eight 6 -year-olds (range $=6$ years, 2 months to 6 years, 10 months; $M=6$ years, 6 months), and eight 7 -year-olds (range $=7$ years, 1 month to 8 years; $M=7$ years, 4 months). Children were recruited from several schools serving ethnically diverse populations of largely middleclass families.

Procedure. We followed the standard procedures for assessing emotion recognition in children (e.g., Camras \& Allison, 1985; Dashiell, 1927; Harrigan, 1984; Izard, 1971). Participants viewed 12 triptychs: $8 \times 11$ in. $(20.3 \times 27.9 \mathrm{~cm})$ laminated sheets featuring three $2.5 \times 3$ in. $(6.4 \times 7.6$ $\mathrm{cm})$ photographs of the same target, shown from the waist up, displaying three different emotion expressions-pride, happiness, and surprise. One male and one female target posed all expressions, and all stimuli were taken from the set of emotion expressions developed by Tracy and Robins (2004b). Figure 1 shows the two versions of the pride expression used in Experiment 1 . Both versions are equally well identified by adult judges (see Tracy \& Robins, 2004b). For the first version, targets posed with an expanded posture (expanded chest, shoulders pulled back), head tilted slightly back (about 15 degrees), small smile with closed mouth, and arms raised above the head with fists. The second version of the pride expression was identical except that arms were at the target's sides, with hands placed on the hips. Figure 1 also shows examples of the happiness and surprise expressions used in the experiment, which were verified with Ekman and Friesen's (1978) Facial Affect Coding System (FACS). We also included a nonstandard version of the surprise expression in which targets posed with arms raised at the elbow and hands open with palms forward, to serve as a "foil" to the first version of the pride expression. ${ }^{4}$

For each triptych, children were asked to "point to the photo where Joe [Jan] is feeling proud [surprised, happy]" ${ }^{, 5}$ and to respond by pointing to one of the three photos. Participants were asked to identify each emotion four times; each emotion was featured in each position within the triptych (left, middle, or right) four times, and each position was the correct answer four times. The order of questions and triptychs was varied among participants, and there were no order effects on pride recognition. The 8-min procedure occurred in a quiet room with a female experimenter.

\section{Results and Discussion}

Figure 2 shows emotion recognition rates for pride, happiness, and surprise for children ages 3 to 7 years. Mean pride recognition across age groups was $59 \%$, which is significantly greater than

\footnotetext{
${ }^{3}$ Recent evidence suggests that an implicit sense of self, and the ability to distinguish between self and other, may emerge as early as 2 months of age (e.g., Rochat \& Striano, 2002). However, self-conscious emotions such as pride are thought to require a more explicit, conceptual understanding of self, which seems to emerge somewhat later (Lewis, 2000; Tracy \& Robins, 2004b).

${ }^{4}$ Surprise recognition rates are reported for the standard surprise expression because this is the expression accepted in the emotion literature.

${ }^{5}$ Pseudonyms of the photographed adults posing emotional expressions were used in the participant instructions.
} 

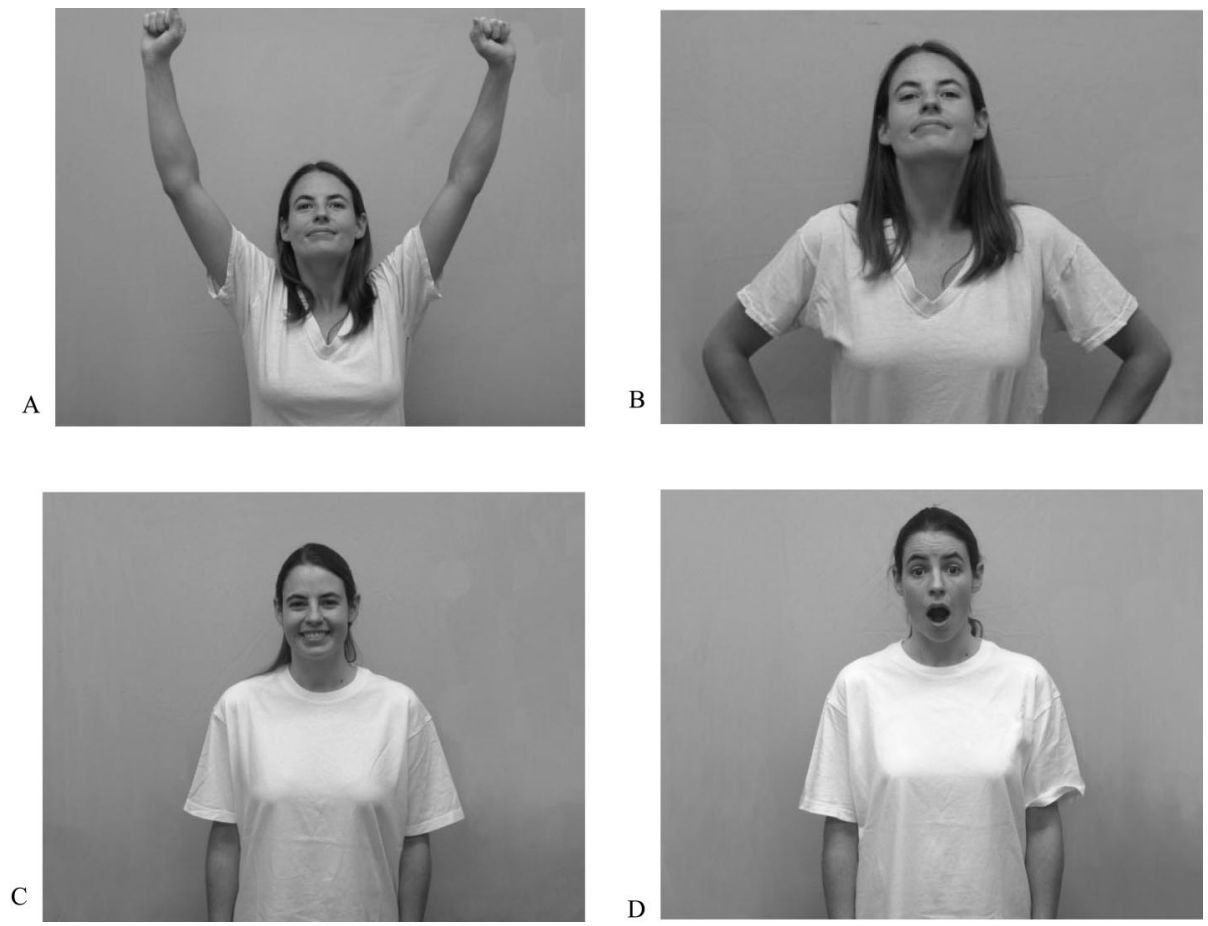

Figure 1. Examples of stimuli used in the present research. Expressions A and B represent the two versions of the pride expression, Expression $\mathrm{C}$ represents the happiness expression, and Expression D represents the surprise expression.

chance (i.e., 33\%) according to the binomial test $(p<.05)$. Pride recognition did not vary as a function of participant gender, target gender (i.e., gender of the poser), or version of the pride expression (i.e., arms up vs. hands on hips). Nor did we find a Participant Gender $\times$ Target Gender interaction on pride recognition. When pride was not identified correctly, it was confused with happiness $76 \%$ of the time and surprise $24 \%$ of the time. This ratio (76:24) was similar for both versions of the pride expression and for both male and female targets, and happiness was the most frequent error at every age level. ${ }^{6}$ Pride recognition rates did not differ when the nonstandard versus standard surprise expression was included as a distractor (57\% vs. $61 \%$, respectively). However, children were

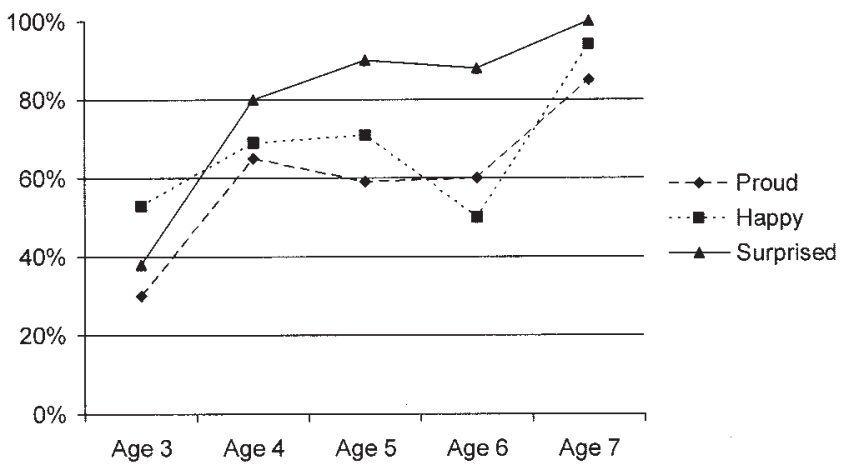

Figure 2. Recognition rates for pride, happiness, and surprise expressions across age groups in Experiment $1 . N=50$. slightly more likely to mistakenly label the nonstandard surprise expression as pride (33\% vs. $21 \%$ of pride-identification errors).

To determine when pride recognition first emerges, we computed binomial tests at each age. Recognition was not significantly greater than chance at age 3 years $(30 \%, n s)$, but it was at 4 years of age $(65 \%, p<.05)$. Pride recognition increased across age groups, as based on a polynomial contrast, $F(1,49)=10.16, p<$ .05. Post hoc Bonferroni tests revealed a significant difference between the 3-year-old (30\%) and the 7-year-old recognition rates $(85 \%, d=.54, p<.05)$, with all other age differences not significant. Moreover, there were no significant interactions between linear age and participant gender, target gender, or version of the pride expression. Overall, these results suggest that children can accurately recognize the pride expression by age 4 and that recognition improves from age 3 to 7 years.

The results were similar when we examined the percentage of children who recognized the pride expression at least half the time (i.e., two of four photos). In this more child-centered analysis, 74\% of children overall showed correct pride recognition (across both versions of the expression); however, whereas $45 \%$ did so at age $3,90 \%$ did so at age 4 . By age $7,100 \%$ of the children correctly identified pride at least twice.

We next compared pride-recognition rates with recognition rates for happiness and surprise. Pride recognition was not significantly

\footnotetext{
${ }^{6}$ Conversely, when children were asked to identify happiness, the most frequent error was pride (79\% of errors). When surprise was not correctly identified, it also was most frequently confused with pride ( $71 \%$ of errors).
} 
different from happiness recognition (67\%) across all age groups or at any particular age. Both pride and happiness recognition rates were lower overall than surprise recognition rates $(80 \%), t \mathrm{~s}(49)=$ 3.69 and $2.54, d \mathrm{~s}=.62$ and .38 , respectively, $p \mathrm{~s}<.05$. However, recognition for pride and surprise differed significantly only at age 5 years, $t(14)=2.74, d \mathrm{~s}=1.10$ and 7.00 , and $t(7)=2.38, d=$ 1.19 , respectively, both $p \mathrm{~s}<.05$, and recognition for happiness and surprise differed significantly only at age 6 years, $t(7)=2.65$, $d=1.00, p<.05$. We did not find an interaction between emotion (pride, happiness, surprise) and age group, suggesting that pride, happiness, and surprise recognition showed similar age trends (see Figure 2). Like pride recognition, happiness and surprise recognition increased across age groups, as based on polynomial contrasts, $F_{\mathrm{s}}(1,49)=4.69$ (happiness) and 14.51 (surprise), both $p \mathrm{~s}<.05{ }^{7}$ Recognition for happiness emerged earlier-it was significantly greater than chance at 3 years of age $(53 \%, p<.05)$. Surprise recognition was not significantly greater than chance at age 3 $(38 \%)$ but was at age $4(80 \%, p<.05)$.

These results demonstrate that (a) children can recognize the pride expression by 4 years of age - the same age at which they first consistently recognize surprise and, as has been found previously, all other basic emotions except happiness, which emerges earlier (Camras \& Allison, 1985; Izard, 1971); (b) children 4 to 7 years of age recognize pride as well as they recognize happiness; (c) pride-recognition rates increase across childhood; and (d) the trajectory of pride-recognition rates across childhood is similar to the trajectories of happiness- and surprise-recognition rates.

One methodological question regarding these findings is whether pride recognition was inflated by children's ability to deduce the correct answer through a process of elimination, assuming that they know the surprise and happiness expressions. Arguing against this possibility is the fact that errors in pride recognition were systematic. Like adults, children most frequently mislabeled pride as happiness (76\% of pride errors), suggesting that they were not randomly guessing about an unknown entity but rather were thoughtfully choosing among the options. Furthermore, it is not clear that young children are capable of consistently implementing a process of elimination rule. Overman, Bachevalier, Miller, and Moore (1996) found that children under the age of 6 years have difficulty performing a similarly deductive task of picking the odd one out of a set of three objects without extensive training. However, the Overman et al. task requires understanding a conceptual similarity, whereas in the present task the only requirement was that children distinguish between known and unknown emotion terms and apply them to visually distinct expressions. In addition, research on language development has shown that when preschoolers are presented with a set of objects, one of which is unfamiliar, they will apply a novel label to the unfamiliar object (e.g., Markman \& Wachtel, 1988).

To address this potential confound more directly, we conducted a second experiment that replicated the design of Experiment 1 but added two new features. First, children were given the option to say that they "don't see" the target expression in each triptych; thus, if they did not know the word pride or did not know what the pride expression looks like, they could simply say they did not see the expression rather than use some inferential process such as exclusion to select an expression. Second, for some triptychs, we asked children to identify a positive emotion with no distinctive nonverbal expression ("love"); this aspect of the design allowed us to test whether participants would correctly use the "don't see it" response option when asked to identify a positive emotion with no identified expression or whether they would label an expression that they might not know (i.e., pride) as love.

\section{Experiment 2}

\section{Method}

Participants. Twenty-three children (48\% girls) participated in the experiment, including nine 4-year-olds (age range $=4$ years, 1 month to 4 years, 11 months; $M=4$ years, 5 months), nine 5 -year-olds (range $=5$ years to 5 years, 11 months; $M=5$ years, 5 months), and five 6 -year-olds (range $=6$ years, 1 month to 6 years, 11 months; $M=6$ years, 6 months) Children were recruited from several schools serving ethnically diverse populations of largely middle-class families. None of the children who participated in Experiment 1 participated in Experiment 2.

Procedure. The procedure was the same as in Experiment 1, with two exceptions. First, the instructions were changed such that, for every triptych, participants were told, "Point to the picture where Joe [Jan] is feeling proud [happy, surprised], if you see it there. If you don't see a picture of Joe [Jan] feeling proud [happy, surprised], tell me that you don't see it." These instructions provided a response option equivalent to the "none of these are correct" option that has been shown to ameliorate concerns regarding the forced-choice response method (Frank \& Stennett, 2001). Given the concern that children in Experiment 1 may have recognized the pride expression through a process of elimination (i.e., by using an exclusion rule), the inclusion of this option provides a fourth option that prevents children from simply deducing that an unknown emotion label must match the one unknown expression.

To ensure that young children understood these new instructions and considered the "don't see it" option as a viable response, we added four training triptychs to the beginning of the task. These triptychs displayed photographs of three different animals, and children were instructed to "point to the picture of the duck [cow, horse, dog] if you see it here," and to tell the interviewer if they "don't see it." In one of these four training trials, the photo of the target animal was not included. All participants responded to this particular triptych by choosing the "I don't see it" option, indicating that they understood how to use this option and were willing to do so when appropriate.

The second change to the procedure was that 4 new emotion expression triptychs were added to the original 12. Participants were asked to identify a fourth emotion expression in these triptychs: love. In actuality, researchers have not identified a distinct, recognizable, nonverbal expression of love; these four triptychs were replicas of 4 of the original triptychs (2 featuring the male target and 2 featuring the female target) and thus portrayed expressions of happiness, pride, and surprise. The inclusion of these additional triptychs allowed us to test whether children would equally apply both "love" and "pride" labels to the pride expression because they were using an exclusion rule (e.g., "I know what happy and surprise look like; I don't know this expression, so it must be love [or pride]"). That is, if participants in Experiment 1 had chosen the pride expression when given the pride label because they were using an exclusion rule, then participants in the present experiment should do the same when asked to identify love. If, however, participants in Experiment 1 had correctly identified pride because they understood that the pride expression signifies pride, then

\footnotetext{
${ }^{7}$ These effects were replicated when age was treated as a continuous variable (i.e., in months). Age was significantly correlated with recognition for pride $(r=.38)$, happiness $(r=.28)$, and surprise $(r=.46)$, all $p \mathrm{~s}<.05$ Consistent with the results for age groups, we failed to find an interaction between age in months and emotion predicting recognition rates, $F(2$, 47) $=1.46$, ns.
} 
when asked to identify love they should be no more likely to choose the pride expression than either of the other two emotion expressions (i.e., happiness or surprise).

\section{Results and Discussion}

The mean pride-recognition rate across age groups was $60 \%$, which is significantly greater than chance (i.e., 25\%) according to the binomial test $(p<.05)$. This rate is comparable to the mean recognition rate across the same three age groups in Experiment 1 (61\%) despite the addition of an "I don't know" response option. Moreover, $78 \%$ of children recognized the pride expression at least half the time (i.e., in at least two of the four photos), compared with $76 \%$ in Experiment 1 . Pride recognition was also significantly greater than chance within every age group $(M=53 \%$ at age 4 , $58 \%$ at age 5 , and $75 \%$ at age 6 ) and did not differ across age groups, according to a polynomial contrast, $F(1,22)=1.38, n s$. Pride recognition also did not vary as a function of participant gender, target gender (i.e., gender of the poser), or version of the pride expression (i.e., arms up vs. hands on hips). Nor did we find a Participant Gender $\times$ Target Gender interaction on pride recognition.

When pride was not identified correctly, it was confused with happiness $58 \%$ of the time ( $23 \%$ of the total responses to prideidentification questions) and surprise $30 \%$ of the time (12\% of total responses); another $12 \%$ of the time (5\% of total responses) children responded by using the "don't see it" option. This pattern of errors was similar for both versions of the pride expression and for both male and female targets. Thus, although participants did occasionally report not seeing the pride expression when it was present, "don't see it" was the least frequent response. Perhaps most important, inclusion of the "don't see it" response option did not reduce pride-recognition rates, based on a comparison with the findings of Experiment 1.

We next compared pride-recognition rates with recognition rates for happiness and surprise. Pride recognition was not significantly different from happiness recognition $(63 \%)$ or surprise recognition (78\%). The happiness-recognition rate was the same as that found in Experiment 1 for the same age groups, and thus was not substantially affected by inclusion of the "don't see it" option; participants chose this option 3\% of the time when asked to identify happiness. Surprise recognition was slightly lower than in Experiment 1 but also was not substantially affected by inclusion of the "don't see it" option; this response was chosen for surprise $4 \%$ of the time.

We next examined responses to the unknown-entity emotion label "love." Participants chose the "don't see it" option $26 \%$ of the time, significantly more frequently than they chose this option for pride $(5 \%), t(22)=2.54, d=.81$; happiness $(3 \%), t(22)=$ $3.25, d=.92$; and surprise $(4 \%), t(22)=2.75, d=.85$, all $p \mathrm{~s}<$ .05 . The majority of children identified one of the three emotion expressions as love, but there was little agreement about which expression it was: $30 \%$ chose happiness, $29 \%$ chose surprise, and $15 \%$ chose pride. It is important to note that participants were less likely to identify the unknown entity as the pride expression than as any other option. Taken together, these findings suggest that children's accurate recognition of pride, found in both Experiment 1 and Experiment 2, cannot be accounted for simply by children's use of a process of elimination strategy.

\section{General Discussion}

Results of two experiments show that (a) children can recognize the pride expression by age 4 years; (b) 4- to 7-year-old children recognize pride as well as they recognize happiness; (c) pride recognition, like happiness and surprise recognition, improves from age 3 to 7 years; and (d) children's ability to recognize pride cannot be accounted for by the use of an exclusion rule.

The present findings are also informative about when children cannot recognize pride. At 3 years of age, pride recognition rates were not greater than chance, whereas happiness recognition rates were. Thus, children may develop the ability to recognize happiness before they develop the ability to recognize pride. However, happiness appears to be unique in this regard-it is the only emotion expression that 3-year-olds can consistently verbally label (Smiley \& Huttenlocher, 1989). One reason why pride recognition, in particular, may develop later is that children experience pride at a later age than happiness ( 2 and 3 years of age vs. the first 6 months of life; Lewis et al., 1992; Reissland \& Harris, 1991; Stipek et al., 1992). Although the ability to experience an emotion may not be required to identify its expression, experiencing pride may well facilitate a conceptual understanding of the emotion which would likely promote the ability to perceive it in others.

All three emotions showed an interesting developmental pattern: recognition rates increased (albeit nonsignificantly) from age 3 to 4 years and again from age 6 to 7 years but remained relatively stable across ages 4, 5, and 6 (see Figure 1). ${ }^{8}$ Although these apparent trends need to be replicated with larger sample sizes, we can speculate about the reasons underlying what may be two developmental shifts in emotion recognition. The increase from age 3 to 4 years may be due to improvement in children's ability to make fine-tuned distinctions among different types of positive and negative emotions and to verbally label and describe emotional experiences (Lagattuta \& Wellman, 2001, 2002). It is also possible that 3-year-olds are generally more prone to errors because they have difficulty focusing on and engaging in such experimental procedures.

The improvement in pride recognition from age 6 to 7 years may be due to the frequent social comparisons children begin to make at this age (Ruble, 1983). Seven-year-olds pay greater attention to others' accomplishments and thus may be more attuned to others' expressions of pride. In addition, as children gain experience in competitive contexts (both at school and through sports), the importance and salience of social-comparison processes, achievement attributions, and other self-evaluative processes are likely to increase, and, correspondingly, experiences of pride may become more central (Ruble, 1983; Thompson, 1989). These speculative interpretations merit further research to explore the developmental processes that underlie changes in emotion recognition during childhood.

Another important finding that emerged from this research is that children's ability to recognize pride is not due to their ability to deduce the correct response through a process of elimination. Specifically, in Experiment 2, the pride-recognition rate was not

\footnotetext{
${ }^{8}$ As can be seen from Figure 2, there was a small, nonsignificant drop in happiness recognition at age 6. Given the small sample of 6-year-olds $(n=8)$, this drop is likely due to chance and should be replicated before it is interpreted.
} 
affected by allowing children to indicate that they "don't see" the expression in the triptych; in fact, only $5 \%$ of participants selected this response when asked to identify the pride expression, suggesting that they were relatively certain about which expression represented pride. In contrast, children did use the "don't see" option when it was appropriate: All children endorsed this option during the training trials, when a target animal was not present in the triptych, and $26 \%$ of the children used this option when asked to identify a nonpresent expression of love. The current research thus has important implications for future research on emotion recognition in children: The inclusion of a "don't see it" option may provide a way for studies to control for children's ability to use a process of elimination. Although children were not entirely successful at using this option to signify that the love expression was not present (equal percentages identified the happiness and surprise expressions as love), these results may be due to the fact that happiness and pride (and possibly even surprise) may all actually be associated with love (Noftle \& Robins, 2004). ${ }^{9}$

Pride recognition was also not dependent on the presence of highly noticeable features of the expression; in both experiments, recognition rates were equivalent for the version of the pride expression in which the targets' arms were at their sides and the version in which the targets' arms were raised above their heads. Similarly, the fact that participants could differentiate pride from happiness suggests that they took into account cues such as posture and/or head tilt, rather than judging expressions on the basis of facial features (e.g., smile) alone. Previous research suggests that adults who are asked to judge expressions of pride engage in a similar process; adults will not label expressions that lack either the facial or bodily (expanded posture) features as pride. It is possible, however, that children are more attuned to gross features such as posture, and future research should examine whether children would infer pride from the presence of expanded posture alone. As a first step, however, we chose to use the version of the pride expression that has generated highest recognition rates among adults (Tracy \& Robins, 2004b), and we demonstrated that even preschoolers recognize this expression as pride.

The present findings raise broader questions about the experience and expression of pride. For example, can 4-year-olds recognize pride when they have not been cued by emotion choices? Adults are able to recognize pride when open-ended response methods are used, but recognition rates are lower than when a forced-response format is used (Tracy \& Robins, 2004b). Similarly, both adults and children show decreased recognition of the basic emotion expressions when open-ended response methods are used (Boucher \& Carlson, 1980; Harrigan, 1984). However, recognition of pride in everyday social interactions, where contextual cues are available, may be easier than in experiments relying on either open- or closed-ended response methods.

Another conceptual question raised by the present findings is whether children understand the meaning behind the labels they apply to emotion expressions. For example, could the 4-year-old who matches the label "pride" with the pride expression provide a psychologically coherent account of what made the target feel that way? Notably, Harris, Olthof, Terwogt, and Hardman (1987) reported that children under the age of 7 years cannot spontaneously generate appropriate situations that would elicit pride. In addition, Thompson (1989) found that 7-year-olds often attribute pride to a person who has accomplished a task even if the success was due to external (e.g., luck) rather than internal (e.g., effort) factors (see also Graham \& Weiner, 1986).

Finally, our findings raise broader questions about the extent to which pride, as a self-conscious emotion, resembles the basic emotions. These results, combined with other recent research (e.g., Lewis et al., 1992; Tracy \& Robins, 2004a, 2004b), suggest that pride may fit within both the self-conscious and the basic-emotion categories and that perhaps the boundaries between the two categories are less clear-cut than some emotion theorists have argued. Like other self-conscious emotions (e.g., shame), pride is cognitively complex, does not appear to be experienced by very young children, and has a complex nonverbal expression that includes bodily as well as facial components. Yet, the present findings show that, like the basic emotions, pride is recognized by both young children and adults. Moreover, age differences in pride recognition are highly similar to age differences in happiness and surprise recognition. However, before reaching any conclusion on the extent to which pride may be considered a basic emotion, research must examine whether the expression is universally recognized, a criterion typically considered the "gold standard" for basic emotions. We recently found preliminary evidence suggesting that pride may meet this standard: Recognition rates were well above chance among a sample of nonliterate individuals from Burkina Faso, Africa, who are almost entirely isolated from Western culture (Tracy \& Robins, 2005). Nonetheless, further research is needed to explore this issue as well as the overarching similarities and differences between basic and self-conscious emotions.

${ }^{9}$ Noftle and Robins (2004) found that $93 \%$ of 180 participants who described a prototypical love experience reported also feeling at least some degree of happiness, and $68 \%$ reported also feeling at least some degree of pride.

\section{References}

Belsky, J., \& Domitrovich, C. (1997). Temperament and parenting antecedents of individual difference in three-year-old boys' pride and shame reactions. Child Development, 68, 456-466.

Boucher, J. D., \& Carlson, G. E. (1980). Recognition of facial expression in three cultures. Journal of Cross-Cultural Psychology, 11, 263-280.

Bretherton, I., \& Beeghly, M. (1982). Talking about internal states: The acquisition of an explicit theory of mind. Developmental Psychology, 6, 906-921.

Campos, J. J., Barrett, K. C., Lamb, M. E., Goldsmith, H. H., \& Stenberg, C. (1983). Socioemotional development. In M. M. Haith \& J. J. Campos (Eds.), Handbook of child psychology: Vol. 2. Infancy and developmental psychobiology (4th ed., pp. 783-915). New York: Wiley.

Camras, L. A., \& Allison, K. (1985). Children's understanding of emotional facial expressions and verbal labels. Journal of Nonverbal Behavior, 9, 84-94.

Dashiell, J. F. (1927). A new method of measuring reactions to facial expression of emotion. Psychological Bulletin, 24, 174-175.

Ekman, P., \& Friesen, W. V. (1978). Facial action coding system: Investigator's guide. Palo Alto, CA: Consulting Psychologists Press.

Ekman, P., Sorenson, E. R., \& Friesen, W. V. (1969). Pan-cultural elements in facial displays of emotion. Science, 164, 86-88.

Felleman, E. S., Barden, R. C., Carlson, C. R., Rosenberg, L., \& Masters, J. C. (1983). Children's and adults' recognition of spontaneous and posed emotional expressions in young children. Developmental Psychology, 19, 405-413. 
Frank, M. G., \& Stennett, J. (2001). The forced-choice paradigm and the perception of facial expressions of emotion. Journal of Personality and Social Psychology, 80, 75-85.

Graham, S., \& Weiner, B. (1986). From an attributional theory of emotion to developmental psychology: A round-trip ticket? Social Cognition, 4, 152-179.

Harrigan, J. A. (1984). The effects of task order on children's identification of facial expressions. Motivation and Emotion, 8, 157-169.

Harris, P. L., Olthof, T., Terwogt, M. M., \& Hardman, C. E. (1987). Children's knowledge of the situations that provoke emotion. International Journal of Behavioral Development, 10, 319-343.

Izard, C. E. (1971). The face of emotion. East Norwalk, CT: AppletonCentury-Crofts.

Keltner, D., \& Buswell, B. N. (1997). Embarrassment: Its distinct form and appeasement functions. Psychological Bulletin, 122, 250-270.

Lagattuta, K. H., \& Wellman, H. M. (2001). Thinking about the past: Early knowledge about links between prior experience, thinking, and emotion. Child Development, 72, 82-102.

Lagattuta, K. H., \& Wellman, H. M. (2002). Differences in early parentchild conversations about negative versus positive emotions: Implications for the development of psychological understanding. Developmental Psychology, 38, 564-580.

Lewis, M. (2000). The emergence of human emotions. In M. Lewis \& J. M. Haviland-Jones (Eds.), Handbook of emotions (2nd ed., pp. 265-280). New York: Guilford Press.

Lewis, M., Alessandri, S. M., \& Sullivan, M. W. (1992). Differences in shame and pride as a function of children's gender and task difficulty. Child Development, 63, 630-638.

Lewis, M., \& Brooks-Gunn, J. (1979). Social cognition and the acquisition of self. New York: Plenum Press.

Markman, E. M., \& Wachtel, G. F. (1988). Children's use of mutual exclusivity to constrain the meaning of words. Cognitive Psychology, 20, $121-157$.

Mascolo, M. F., \& Fischer, K. W. (1995). Developmental transformations in appraisals for pride, shame, and guilt. In J. P. Tangney \& K. W. Fischer (Eds.), Self-conscious emotions: The psychology of shame, guilt, embarrassment, and pride (pp. 64-113). New York: Guilford Press.

Noftle, E. E., \& Robins, R. W. (2004). The complexity of emotion experience: Co-occurrence of emotions in emotion episodes [unpublished data].

Odom, R. D., \& Lemond, C. M. (1972). Developmental differences in the perception and production of facial expressions. Child Development, 43, $359-369$.

Overman, W., Bachevalier, J., Miller, M., \& Moore, K. (1996). Children's performance on "animal tests" of oddity: Implications for cognitive processes required for tests of oddity and delayed nonmatch to sample. Journal of Experimental Child Psychology, 62, 223-242.

Reissland, N., \& Harris, P. (1991). Children's use of display rules in pride-eliciting situations. British Journal of Developmental Psychology, 9, 431-435.

Rochat, P., \& Striano, T. (2002). Who's in the mirror? Self-other discrimination in specular images by four- and nine-month-old infants. Child Development, 3, 35-46.

Ruble, D. N. (1983). The development of social-comparison processes and their role in achievement-related self-socialization. In E. T. Higgins, D. N. Ruble, \& W. W. Hartup (Eds.), Social cognition and social development (pp. 134-157). Cambridge, England: Cambridge University Press.

Smiley, P., \& Huttenlocher, J. (1989). Young children's acquisition of emotion concepts. In C. Saarni \& P. Harris (Eds.), Children's understanding of emotion (pp. 27-49). Cambridge, England: Cambridge University Press.

Stipek, D., Recchia, S., \& McClintic, S. (1992). Self-evaluation in young children. Monographs of the Society for Research in Child Development, 57(1), Serial No. 226

Thompson, R. A. (1989). Causal attributions and children's emotional understanding. In C. Saarni \& P. Harris (Eds.), Children's understanding of emotion (pp. 117-150). Cambridge, England: Cambridge University Press.

Tracy, J. L., \& Robins, R. W. (2004a). Putting the self into self-conscious emotions: A theoretical model. Psychological Inquiry, 15, 103-125.

Tracy, J. L., \& Robins, R. W. (2004b). Show your pride: Evidence for a discrete emotion expression. Psychological Science, 15, 194-197.

Tracy, J. L., \& Robins, R. W. (2005). Evidence for universality of nonverbal expressions of pride and shame. Manuscript submitted for publication.

Walker-Andrews, A. S., \& Dickson, L. R. (1997). Infants' understanding of affect. In S. Hala (Ed.), The development of social cognition (pp. 161-186). West Sussex, England: Psychology Press.

Received August 10, 2004

Revision received October 29, 2004

Accepted November 17, 2004 